\title{
Autosomal recessive spastic paraplegia type 25
}

INSERM

\section{Source}

INSERM. (1999). Orphanet: an online rare disease and orphan drug data base. Autosomal recessive spastic paraplegia type 25. ORPHA:101005

Autosomal recessive spastic paraplegia type 25 (SPG25) is a rare, complex type of hereditary spastic paraplegia characterized by adult-onset spastic paraplegia associated with spinal pain that radiates to the upper or lower limbs and is related to disk herniation (with minor spondylosis), as well as mild sensorimotor neuropathy. The SPG25 phenotype has been mapped to a locus on chromosome 6q23-q24.1. 